\title{
EPISTEMOLOGIAS SUBVERSIVAS EM LABORATÓRIO - O LAMPEAR E O MOVIMENTO OCUPA CERES NA UFRN
}

\author{
SUBVERSIVE EPISTEMOLOGIES IN LABORATORY - \\ LAMPEAR AND THE MOVEMENT OCCUPIES CERES IN UFRN
}

\author{
Fernando Bomfim Mariana ${ }^{1}$ \\ Laiza Brunett Alves de Araújo
}

\section{RESUMO}

Durante o ano de 2016, diversos movimentos sociais se insurgiram contra as políticas econômicas alavancadas pelos Governo Federal, em especial a PEC 55. Na Universidade Federal do Rio Grande do Norte, o LABORATÓRIO INTERNACIONAL DE MOVIMENTOS SOCIAIS E EDUCAÇÃO POPULAR (LAMPEAR) e o MOVIMENTO OCUPA CERES realizaram diversas ações diretas e atividades acadêmicas voltadas para a indissociabilidade entre produção de conhecimento e emancipação social, possibilitando novas formas de aprendizagem intrínsecas à luta social. Este artigo revela alguns pressupostos teóricos dinamizados pelo LAMPEAR e um relato de caso das ocupações desencadeadas pelos estudantes na UFRN através do MOVIMENTO OCUPA CERES.

Palavras-chave: movimentos sociais, ocupações, epistemologias emancipatórias.

\begin{abstract}
During the year 2016, several social movements rebelled against the economic policies leveraged by the Federal Government, especially PEC 55. At the Federal University of Rio Grande do Norte, Brazil, the INTERNATIONAL LABORATORY OF SOCIAL MOVEMENTS AND POPULAR EDUCATION (LAMPEAR) and the MOVEMENT OCUPA CERES carried out several direct actions and academic activities focused on the inseparability between knowledge production and social emancipation, making possible new forms of learning intrinsic to the social struggle. This article reveals some theoretical assumptions dynamized by LAMPEAR and a case report of the occupations triggered by the students in the UFRN through the OCUPA CERES social movement.
\end{abstract}

Keywords: social movements, occupations, emancipatory epistemologies.

\footnotetext{
${ }^{1}$ Historiador pela Faculdade de Filosofia, Letras e Ciências Humanas da Universidade de São Paulo (1997), com mestrado (2003) e doutorado (2008) em Educação pela Faculdade de Educação da USP. Professor Adjunto do Departamento de Educação do Centro de Ensino Superior do Seridó (CERES) da Universidade Federal do Rio Grande do Norte (UFRN). E-mail: fbmariana@hotmail.com.

2 Graduanda do curso de Pedagogia da Universidade Federal do Rio Grande do Norte (UFRN). E-mail: laizabrunett@outlook.com.br.
} 


\section{APRESENTAÇÃO}

\section{O LABORATÓRIO INTERNACIONAL DE MOVIMENTOS SOCIAIS E} EDUCAÇÃO POPULAR (LAMPEAR) foi um espaço coletivo interinstitucional sediado no Centro de Ensino Superior do Seridó (CERES) da Universidade Federal do Rio Grande do Norte (UFRN), desenvolvendo suas atividades no período entre outubro de 2010 a fevereiro de 2018. O LAMPEAR procurou articular iniciativas anticapitalistas voltadas para a emancipação social, estimulando a busca pela condição humana maravilhosa no sertão e em outras localidades do planeta. Ao mesmo tempo, denunciou a miséria da vida cotidiana em que nos encontramos submetidos, ora devido às ingerências de instituições totalitárias contemporâneas (em especial as grandes empresas transnacionais e o Estado), ora pela falta de iniciativa e/ou desorganização popular em tentar romper com as amarras de escravidão social, política, econômica e cultural da atualidade.

Ao reconhecer o papel fundamental dos movimentos sociais para as atuais concepções de educação popular, o LAMPEAR se entrelaçou com diversos segmentos da sociedade civil organizada para construir conhecimentos/habilidades fundamentais para a autonomia social a partir de renovadas formas de relação humana. Nesse sentido, o LAMPEAR consolidou desde o ano de 2010 uma série de ações de extensão universitária que, ao lado de práticas de ensino e pesquisa na UFRN, imprimiram novas perspectivas para a relação entre universidade e sociedade.

No ano de 2016, a partir das ofensivas de medidas executivas de um Governo Federal ilegítimo - instituído após o processo de impeachment da presidenta do Brasil Dilma Rousseff - contrárias aos direitos sociais já garantidos pela Constituição Brasileira, uma série de movimentações sociais tomaram os espaços públicos de debate nas Universidades públicas. No caso do campus do CERES da UFRN em Caicó, o coletivo de estudantes OCUPA CERES iniciou ações diretas que puderam proporcionar reflexões e formas de resistência popular próprias das lutas sociais emancipatórias. Uma das principais formas de ação direta foi a realização de uma ocupação política do campus universitário, fato que provocou enorme onda de discussões políticas acerca da sociedade no Brasil contemporâneo e do próprio papel da Universidade pública. 
Antes de apresentar o relato de caso do MOVIMENTO OCUPA CERES, acreditamos que seja imprescindível discorrer sobre alguns princípios teórico-filosóficos que embasaram as metodologias de trabalho no LAMPEAR durante quase uma década de atividades, uma vez que tais estudos indicam epistemologias subversivas e emancipatórias que facilitam a compreensão do mundo ao nosso redor e das possibilidades práticas de mobilizações sociais voltadas para a liberdade humana.

\section{METODOLOGIA}

As metodologias utilizadas nas atividades do LAMPEAR e do MOVIMENTO OCUPA CERES estão ancoradas em ações educativas dialógicas e coletivas, em especial orientadas pelos preceitos filosóficos de dialogicidade de FREIRE (1983).

Nessa perspectiva, os caminhos metodológicos horizontalizados estiveram organizados em rodas de conversas, em que todos os participantes pudessem expor suas ideias e pensamentos. Em relação aos estudos que embasaram as atividades do LAMPEAR, podemos citar quatro linhas epistemológicas emancipatórias, sejam explicitadas abaixo a partir de suas principais referências teóricas ${ }^{3}$ :

\section{O CONCEITO DE AUTONOMIA NA OBRA DE CASTORIADIS}

O conceito de autonomia utilizado na obra de Cornelius Castoriadis subsidia a investigação acerca das contradições entre práticas autônomas e heterônomas, além de elucidar a dinâmica de auto-institucionalidade que caracteriza os movimentos autônomos.

No nível do indivíduo, Castoriadis se apropria da expressão freudiana Wo Es war, soll Ich werden (Onde era o Id, será o Ego) para exemplificar, psicanaliticamente, a aproximação do Ego com a esfera consciente; o Id com o inconsciente em geral.

"Ego, consciência e vontade, deve tomar o lugar das forças obscuras, que, em
mim, dominam, agem por mim. (...) O Ego deve tomar o lugar do $I d-$ isso
não pode significar nem a supressão das pulsões, nem a eliminação ou a

\footnotetext{
${ }^{3}$ Tais referências teóricas foram sintetizadas e desenvolvidas a partir da dissertação de Mestrado "Autonomia, cooperativismo e Movimentos dos Trabalhadores Rurais Sem Tera (MST): contribuições educativas para autogestão e pedagogias de levante" (MARIANA, 2003).
} 


\section{Revista \\ Debates Insubmissos}

reabsorção do inconsciente. Trata-se de tomar seu lugar na qualidade de instância de decisão" (CASTORIADIS, 1982, p. 125).

Não podemos negar os desejos e necessidades advindos do mundo social e introjetados em nossa esfera inconsciente. Para Castoriadis, a autonomia não é a eliminação do discurso do Outro, mas "a instauração de uma outra relação entre o discurso do Outro e o discurso do sujeito" (1982, p. 126)

Nesse sentido, a consciência na tomada de decisão em assembleias ou qualquer outro mecanismo de gestão democrática é condição primeira para a inexistência de relações totalitárias criadas por determinada institucionalidade sobre um indivíduo.

A dimensão social da autonomia encontra-se justamente no fato da vida em sociedade, ou seja, na contínua presença do discurso do Outro em nosso ser individual. O discurso do Outro assume formas variadas, podendo se materializar nos mecanismos de mercado, em programas televisivos, utilização de celulares e computadores, na vigilância, nas prisões.

Ao elaborar tal discurso em nossa ação inter-subjetiva, deslocamos a questão da autonomia do nosso plano individual para uma empreitada coletiva. Essa ação inter-subjetiva representa nossa existência social e histórica. Para o autor, o social-histórico "é a união e a tensão da sociedade instituinte e da sociedade instituída, da história feita e da história se fazendo" (CASTORIADIS, 1982, p. 131). As necessidades humanas dentro da sociedade capitalista atuam justamente na situação de tensão entre a instituição imaginária de novos e ilimitados desejos (em grande parte materializados em novos serviços e ilimitadas mercadorias) e os anseios conscientemente advindos do indivíduo.

$\mathrm{Na}$ direção inversa da autonomização das instituições (jurídicas e não jurídicas) perante o indivíduo, ou seja, da perda do controle do ser humano sobre os meios e os fins de qualquer relação instituída na sociedade, Castoriadis propõe no plano político a autogestão das instituições e a consequente abolição de relações hierárquicas. Para o autor, uma sociedade autogerida é uma sociedade onde todas as decisões são tomadas pela coletividade. $\mathrm{Na}$ medida em que se expande, as estruturas de poder na sociedade autogerida são ocupadas por delegados eleitos diretamente na sua comunidade ou local de trabalho, com mandatos 
revogáveis e rotativos, em substituição a qualquer forma de direção hierarquizada, burocratizada ou especializada que, inevitavelmente, escapam ao poder da coletividade.

Toda decisão coletiva é tomada com conhecimento de causa. O monopólio de acesso a informações e o ritmo desigual de construção de conhecimentos comuns para a decisão coletiva resulta na hierarquia de comando. $\mathrm{Na}$ sociedade hierárquica, porém, o saber e a competência especializados permitem a técnicos e/ou administradores tomarem decisões coletivas, mesmo causando conflitos perpétuos ou desperdícios gigantescos.

Numa sociedade autogerida, a incompatibilidade com uma hierarquia de direção não é menor do que a incompatibilidade com a hierarquia de salários e rendimentos, uma vez que não existem critérios objetivos para fundar tal desigualdade.

No trabalho produtivo, a substituição da motivação econômica pela motivação social desabrocha a invenção, a criatividade e a motivação para a realização da atividade, ainda mais quando o fruto do trabalho se demonstra compatível com necessidades coletivas reais na sociedade.

4. ESTADO AMPLO E ESTADO RESTRITO NAS OBRAS DE JOÃO BERNARDO E

\section{LÚCIA BRUNO}

No processo de expansão do mundo da mercadoria, o Mercado capitalista internacionalizado conta com um de seus tradicionais aliados históricos: o Estado. Atualmente, a íntima relação entre Mercado e Estado tem suscitado interessantes debates a respeito da soberania do Estado-nação em relação ao Mercado global. Em Transnacionalização do capital e fragmentação dos trabalhadores, João Bernardo oferece um interessante recorte do perfil do Estado capitalista, colaborando para a continuidade da análise deste tema:

[...] chamo Estado Restrito ao conjunto das instituições que compõe o governo, o parlamento e os tribunais, ou seja, aos poderes executivo, legislativo e judiciário. [...] $\mathrm{O}$ que me leva a admitir que exista no aparelho global do Estado outra esfera, mais ampla? Em tudo o que diz respeito à organização interna das empresas, os patrões e os gestores escolhem os sistemas de administração e organizam a força de trabalho, o que constitui uma forma de poder legislativo. Além disso, eles estabelecem as hierarquias, definindo a amplitude das decisões possíveis de ser tomadas em cada escalão, 


\section{Revista \\ Debates Insubmissos}

e impõe as normas de trabalho, o que constitui uma forma de poder executivo. Finalmente, os proprietários das empresas ou os seus administradores avaliam o desempenho de cada trabalhador, concedendo prêmios de produtividade ou impondo multas e outros tipos de punição, inclusive a demissão, o que constitui uma forma de poder judiciário. E eles fazem-no numa esfera que é em grande medida alheia aos condicionalismos impostos pelo Estado Restrito. O governo, o parlamento e os tribunais reconhecem aos proprietários privados e aos gestores uma enorme latitude na administração, na condução e na punição da força de trabalho, ou seja, reconhecem-lhe uma verdadeira soberania. E qualquer exercício de um poder soberano é, por si só, uma atividade política. Ora, se a organização da economia é ela própria, diretamente, um poder político, então o seu âmbito de ação é muitíssimo vasto. Por isso lhe chamo Estado Amplo [...]. Na forma como o concebo, o Estado capitalista é sempre resultado de uma conjugação entre o Estado Amplo e o Estado Restrito. (BERNARDO, 2000, p. 11-12)

No início do processo de fortalecimento das empresas transnacionais, o Estado Restrito providenciara toda a infraestrutura necessária para a viablização da implantação e desenvolvimento de determinadas forças produtivas. Nessa fase inicial, o Estado Amplo não poderia arcar sozinho com as despesas básicas para sua expansão. A partir da cooptação de partes do Estado Restrito, as empresas estruturam um poder para além das portas da unidade de produção. Em Reestruturação capitalista e Estado Nacional (1999), Lúcia Bruno discorre sobre as instituições do Estado Amplo, citando essencialmente:

- Council on Foreign Relations (CFR), criado em 1918 nos EUA, composto por altos dirigentes dos maiores grupos norte-americanos, militares, ministros de Estado, intelectuais e dirigentes da grande mídia;

- Business Council (BC), em 1933 nos EUA, órgão ligado ao Departamento de Comércio do Estado, reunindo sessenta empresários;

- Political and Economical Planning (PEP), em 1931 na Grã-Bretanha, composto por representantes de grandes grupos econômicos, militares, intelectuais, políticos, jornalistas;

- Committee for Economic Development (CED), em 1942 nos EUA, composto por representantes de empresas multinacionais. Ao lado do CFR, formulou as diretrizes básicas para a criação da OTAN, do FMI e do Banco Mundial.

- CEPES (Comitê Europeu para o Progresso Econômico e Social), a partir da década de 40 em diversos países europeus; 
- Comitê de Desenvolvimento Econômico Japonês (Keisai Doyukai), fundado em 1946, baseada em grandes empresas japonesas. Surgiu como parte da rede CED (EUA) e CEPES (Europa), desenvolveu-se posteriormente como órgão consultor do MITI (Ministério da Indústria e Comércio Internacional).

Outras instituições organizadas nesta mesma perspectiva, tais como a Organização Mundial do Comércio (OMC) que, a partir de janeiro de 1995, substituiu o GATT - Acordo Geral de Tarifas e Comércio. A OMC, juntamente com outros organismos, como a CCI (Câmara de Comércio Internacional), a OCDE (Organização para a Cooperação e o Desenvolvimento Econômico) e o FMI (Fundo Monetário Internacional), articula cerca de 500 megaempresas que dominam $2 / 3$ do comércio no mundo.

Nessa conjuntura mundial, e com o auxílio de um sindicalismo atrelado a co-gestão nas empresas em busca de melhores resultados na produtividade, o Estado Amplo vem se sobrepondo ao Estado Restrito, internacionalizando suas esferas de poder e construindo os processos de democracia e globalização da economia. Obviamente que as partes do Estado Restrito aberto a participação popular nos atuais regimes democráticos restringem-se a esferas

demasiadamente dependentes daquelas já cooptadas pelo Estado Amplo. As privatizações, dentro desse prisma, dinamizam a fluência das relações econômicas internacionais, ultrapassando possíveis obstáculos encontrados no âmbito do Estado Restrito.

\section{ZONAS AUTÔNOMAS TEMPORÁRIAS}

O conceito elaborado por Hakim Bey de zona autônoma temporária auxilia na reflexão sobre as ações diretas possíveis no mundo contemporâneo. Para o autor, "um levante representa uma possibilidade muito mais interessante, do ponto de vista de uma psicologia da libertação, do que as bem-sucedidas revoluções burguesas, comunistas, fascistas, etc." (BEY, 2001, p.21).

Tal raciocínio procura questionar o sucesso de revoluções permanentes e, ao mesmo tempo, valorizar os momentos insurgentes temporários autônomos como uma das mais valiosas experiências pedagógicas. Nesses momentos de levante, a auto-institucionalidade é vivida e 
apreendida no cotidiano, o que dificilmente ocorre ao se materializar uma certa ordem revolucionária.

Segundo a obra de Bey, três pressupostos básicos são necessários para a efetivação dinâmica de uma zona autônoma. Inicialmente, a substituição da família nuclear por outros coletivos de convivência cotidiana, tais como bandos, clãs, confrarias, república de crianças, etc.

Outra característica fundamental é a possibilidade de tempos e espaços livres festivos. É no tempo-espaço livre que emerge o potencial de criação do indivíduo e a respectiva construção e fortalecimento da individualidade dentro do coletivo. A importância do sentimento de festividade no tempo-espaço livre invoca "Fourier e seu conceito dos sentidos como base de transformação social - toque do cio e gastrosofia, e seu louvor às negligenciadas implicações do olfato e do paladar" (IDEM, p.24). Na essência da festa, um grupo de seres humanos, frente a frente, "coloca seus esforços em sinergia para realizar desejos mútuos, seja por boa comida ou alegria, por dança, conversa, pelas artes da vida. Talvez até mesmo por prazer erótico ou para criar uma obra de arte comunal, ou para alcançar o arroubamento do êxtase. Em suma, uma união de únicos - como coloca Stirner - em sua forma mais simples, ou então, nos termos de Kropotkin, um básico impulso biológico de ajuda mútua". (IDEM, p. 26-27)

Finalmente, o terceiro momento para uma zona autônoma temporária: o conceito de nomadismo psíquico. A partir da padronização global dos ambientes de sociabilidade humana que "tende a ofuscar toda a diversidade cultural e toda a individualidade para que todo lugar seja igual ao outro" (IDEM, p.27), o autor ressalta o valor do desejo e curiosidade por outros tempos-espaços psíquicos. Descreve estes momentos não apenas através do percurso espacial físico, derivado de movimentações de trabalhadores imigrantes, refugiados, sem-teto, turistas, mas também na possibilidade de utilização consciente de recursos audiovisuais, de telecomunicações, livros, ou mesmo ainda mudança de emprego, estilo de vida, religião, dieta, e outros.

Podemos citar alguns exemplos de práticas históricas nos quais o autor embasou sua teoria sobre as zonas autônomas temporárias. O soviete de Munique (ou a "República do 
Conselho"), de 1919, apresentava características anarquistas que possibilitaram o livre exercício de um poder autônomo comunitário, assim como a insurreição de Kronstadt (1921), contrária ao governo bolchevique, e as movimentações populares durante a Revolução Espanhola (1936-39).

As comunas revolucionárias urbanas na Europa, como a Comuna de Paris, também capitularam os principais aspectos de uma zona autônoma. O grau de autonomia conquistado pela população, mesmo temporariamente, repercutiu "durante e depois destes anos", possibilitando aos anarquistas adquirir "a prática do nomadismo revolucionário, perambulando de revolta em revolta, procurando manter viva em si mesmos a intensidade do espírito que eles experimentaram no momento do levante" (IDEM, p.58), ou seja, sempre ocupar uma localidade geográfica passível do desencadeamento de uma zona autônoma.

Outras experiências de menores proporções também subsidiaram a teoria investigada, tais como a Colônia Roanoke e a Colônia Libertatia, ambas criadas por colonizadores durante a época das grandes navegações e da invasão da América nos séculos XVI e XVII. O elemento central destas experiências foi a sabotagem dos planos de invasão dos territórios americanos, a deserção em massa dos colonizadores, e a rendição aos indígenas, resultando na união entre os povos. Ainda nessa perspectiva, o autor descreve os assentamentos ou comunidades estabelecidas à margem da lei, proliferadas basicamente durante o século XVIII, articuladas por piratas e corsários através de "rede de informações" globais (formada por ilhas ou esconderijos remotos onde os navios trocavam os resultados das pilhagens).

Temporariamente, a zona autônoma é uma zona liberta. Liberta precária e provisoriamente das institucionalidades heterônomas do sistema capitalista. Mesmo não se conjecturando como excludente ao sistema, esta se contrapõe ao heterodeterminado, possibilitando no conflito o desabrochar das contradições e suas possíveis superações.

\section{A INTERNACIONAL SITUACIONISTA}

A Internacional Situacionista (I.S.) foi um movimento internacionalista surgido na década de 50, organizado a partir da crítica ao espetáculo de massas, à arte e ao urbanismo. 
As estratégias heterodoxas da I.S. - fundadas no escândalo, subversão e sabotagem da arte contemporânea - possui no movimento imediato em prol da revolução uma estreita relação com a valorização de levantes enquanto modo de contestação da mercadorização da vida humana na dinâmica de desenvolvimento do capitalismo.

A crítica situacionista denuncia a técnica de controle das massas - desenvolvidas a partir do Estado de Bem Estar Social -, a internacionalização do capital via multinacionais e o deslocamento da propaganda política para a publicidade comercial. Similar pensamento podemos apontar em BERNARDO (1998).

A postura política da I.S. se configurava, antes de tudo, como não doutrinária. Para os situacionistas, o situacionismo é um vocábulo sem sentido, construído abusivamente por antisituacionistas para forjar uma doutrina de interpretação. Execrava rótulos ideológicos, porém orientava-se pelo fim do Estado e da sociedade do espetáculo, e a favor dos Conselhos Operários, da autogestão generalizada e da organização de ocupações. Além disso, a I.S. criticava qualquer forma de mediação, inclusive a artística.

A forma de atuação dos membros da I.S. era a situação construída, traduzida em diversos momentos pela ação performática. Tal situação, construída pela organização coletiva, carregava intrinsicamente um componente pedagógico através de seu jogo de acontecimentos. No espaço dos lazeres, a contribuição da I.S., para este estudo, está na sua crítica ao controle do tempo livre dos seres humanos e à transformação da arte em mercadoria.

A formulação teórica do urbanismo unitário, onde a cidade reservaria um papel central para a participação ativa e encontro dos indivíduos num ambiente criativo e lúdico, também possui grande relevância para o tema. Tal perspectiva procura questionar o funcionalismo da cidade ou, mais além, a caracterização da cidade enquanto fábrica. Ao mesmo tempo, apresenta o conceito de sobretrabalho, isto é, o tempo de vida destinado a atividades complementares ao trabalho heterônomo - tais como tempo de transporte.

Utilizamos alguns desses fundamentos no decorrer das análises a respeito das potencialidades dos movimentos sociais na transformação do modelo organizacional do capitalismo centrado no urbanismo. Além disso, procuro subsidiar interpretações sobre as 
possibilidades de reversão do processo de êxodo rural na atual conjuntura de precarização da vida e do trabalho na cidade e no campo.

Finalmente, a importância do exercício da deriva, proposto pela I.S., nos ajudou a compreender aspectos importantes da vida cotidiana nos assentamentos (e seu respectivo compromisso com modificações neste cotidiano realizadas conscientemente). $\mathrm{O}$ exercício da deriva permite entrar em contato com situações diversas nos cotidianos investigados, ultrapassando as barreiras de um olhar premeditado sobre determinado assunto.

\section{RESULTADOS E DISCUSSÕES}

Dentre os principais resultados de ações político-acadêmicas que se desenvolveram a partir das metodologias dialógicas e coletivas numa perspectiva emancipatória e autônoma, o relato de caso do MOVIMENTO OCUPA CERES e todas as discussões engendradas em suas dinâmicas representam uma das maiores contribuições de inserção coletiva na luta social a partir da vida universitária no campus do CERES/UFRN no município de Caicó-RN.

O movimento OCUPA CERES teve seu início no dia 25/10/17, com cerca de quinze ocupantes estudantes do Centro de Ensino Superior do Seridó (CERES) da Universidade Federal do Rio Grande do Norte, reivindicando a luta social contra a PEC 241 (posteriormente PEC 55) - Proposta de Emenda Constitucional de limitação dos gastos públicos por 20 anos, e que coloca em cheque a ideia de justiça social no País (em especial os investimentos com educação e saúde).

Estudantes-ocupantes estiveram distribuídos inicialmente pelos corredores, dormindo entre barracas e redes, e após conversa com a diretora do campus, foi ocupada uma sala do bloco de sala de aulas. Os ocupantes, em sua maioria, pertenciam ao Movimento Estudantil Autônomo Organizado (MEAO), movimento estudantil atuante no CERES. Em poucos dias foi aumentando o número de ocupantes até atingir o apoio dos estudantes secundaristas (que sempre que possível passavam o diae a noite no campus do CERES). A comida era totalmente doada - ou comprada com dinheiro doado pela comunidade em geral. A cozinha comunitária foi instalada na cantina do CERES com objetos disponibilizados pela comunidade e pelos 
próprios ocupantes. A convivência com o corpo estudantil do campus foi fundamental, pois todos faziam uso da cantina, e aproveitavam para tirar suas dúvidas sobre a ocupação e conhecer um pouco mais da luta. Além do aroma das refeições, a cozinha também exalava sons incentivadores, como a música de Criolo, Mano Chao, Chico Science, Pink Floyd, entre outros - estratégia para chamar a atenção daqueles que não paravam para ouvir as reivindicações. O campus teve sua parte central recheada de cartazes produzidos pelos ocupantes. A seguir seguem as principais reivindicações organizadas pela ocupação:

- Assegurar a não criminalização do movimento, resguardando os participantes de todo tipo de penalidade policial ou acadêmica;

- Tornar os gastos e prioridades do orçamento financeiro do CERES transparentes a todos os discentes do campus, dando ênfase no planejamento para o ano de 2017, de acordo com a redução prevista da verba da Universidade Federal do Rio Grande do Norte (campus central), em função dos ajustes do governo ilegítimo de Michel Temer;

- Pressionar para que o corpo docente local iniciasse uma greve geral de professores;

- Pressionar para que o corpo discente iniciasse uma greve geral estudantil;

- Promover eventos, plenárias e culturais que contribuíssem para a articulação de debates políticos entre todos os estudantes do campus local, as escolas da educação básica e todos os membros da sociedade civil caicoense;

- Lutar pela construção de um Restaurante Universitário no Centro de Ensino Superior do Seridó;

- Promover a articulação do Movimento de Ocupação Estudantil do CERES/Caicó com todas as escolas da cidade, os Institutos Federais de Ensino Médio Técnico, e todas as faculdades e Universidades da região, objetivando a efetivação de um movimento de ocupação regional integrado.

A Ocupação Estudantil dialogava diretamente com toda a comunidade acadêmica do CERES, corpo discente, docente, e técnico-administrativo, através de plenárias diárias, eventos culturais, debates políticos e demais manifestações. O Movimento OCUPA CERES 
não divulgava nomes dos seus participantes com intuito de evitar que membros da sociedade local atribuíssem papéis de liderança a determinados estudantes. É importante esclarecer que a ocupação estudantil foi extremamente horizontal e repudiava a ideia de haver lideranças no movimento. Os ocupantes consideravam a liderança uma forma de oprimir a livre ação da coletividade. O movimento foi apartidário, não defendendo quaisquer partidos, e exaltava a luta pela garantia dos direitos humanos (saúde, educação, moradia, segurança, liberdade de expressão, entre outros).

Ao mesmo tempo, havia a preocupação para que a segurança dos estudantes-ocupantes não fosse afetada, uma vez que certas pessoas da comunidade acadêmica desconheciam o trabalho que vinha sido realizado na ocupação, e por vezes preferiram atribuir estereótipos negativos ao movimento em detrimento de buscar compreensão sobre a ação política. Contudo, a identidade dos integrantes do OCUPA CERES não era nenhum segredo, podendo facilmente ser reconhecida em uma visita ao Bloco B do campus do CERES que estava completamente ocupado.

No dia 26 de outubro de 2016 foi realizado um abaixo-assinado entre o corpo discente, com o objetivo de organização da I Assembleia Geral Estudantil do CERES. No dia primeiro de novembro tivemos um dos maiores problemas durante a ocupação: as falsas notícias espalhadas sobre um suposto acordo com o Instituto Nacional de Estudos e Pesquisas Educacionais Anísio Teixeira (INEP). Em reunião com um representante do INEP e a direção do CERES, a Ocupação Estudantil do CERES estabeleceu um acordo para desocupar o bloco do campus universitário para a aplicação do Exame Nacional do Ensino Médio (ENEM). O representante do Ministério da Educação (MEC) insistiu que o bloco fosse desocupado no mesmo instante da reunião - algo inviável para a dimensão estrutural da ocupação. Com isso, o ENEM não foi aplicado, e a decisão final de cancelar a prova foi única e exclusiva do INEP - mas os boatos propagandeados foi que o OCUPA CERES não iria desocupar o bloco para o ENEM. Desde o início da ocupação houve a preocupação em não prejudicar os estudantes que realizariam as provas, e por isso foi firmado um acordo de desocupação com a direção do CERES e representantes do governo federal. Tal acordo foi descumprido por parte dos representantes do governo, uma vez que seria possível realocar as provas e tomar outras 
medidas que não prejudicassem os estudantes. Mas essa atitude intencionava, claramente, inflamar a opinião pública contra as ocupações.

No dia dois de novembro sofremos uma repressão inesperada. Em virtude de falta de energia em todo o CERES durante a noite, um sujeito aparentemente alcoolizado se aproveitou da fragilidade da ocupação. Apresentou comportamento agressivo, retirou cartazes e faixas que estavam fixados na entrada da UFRN, enquanto xingava e tentava intimidar os ocupantes com um pedaço de madeira na sua mão. Foi realizado um boletim de ocorrência junto à direção do campus contra este ato violento e irracional direcionado a uma ocupação legítima e pacífica.

No dia três de novembro, a partir do conjunto de assinaturas suficientes reunidas em abaixo-assinado, foi realizada a primeira Assembleia Estudantil do CERES - Caicó/Currais Novos. A Assembleia realizou-se seguindo o estatuto do Diretório Acadêmico do CERES. Sua pauta principal foi o indicativo de greve geral estudantil. A Assembleia iniciou por volta das 20:00hs e seu término foi por volta das 22:00hs. Após os debates, a maioria expressiva decidiu por greve. Dentre as decisões realizadas na noite estavam o início da greve no dia 11/11/2016. Formou-se de maneira voluntária a comissão eleitoral que viria a organizar a eleição do comando de greve. E foi decidido também quais seriam os objetivos da greve, como a construção de um restaurante universitário no CERES-CAICÓ; um posicionamento oficial do CERES e da UFRN contra a PEC 55; a retirada definitiva dessa proposta de emenda constitucional da pauta do congresso; a não criminalização da greve. Foi acordado que a greve não incluiria a paralisação das atividades de bolsa e laboratórios. O foco era a paralisação das aulas, e ficou decidida a deflagração da greve estudantil a partir da data indicada.

Nesta mesma data iniciou-se a paralisação dos docentes da UFRN - que teve duração de apenas uma semana, retomando as atividades no dia 17/11/2016. Durante esta semana houveram diversas mobilizações na UFRN. O sindicato dos professores da UFRN (ADURN), o sindicato dos servidores técnico-administrativos (SINTEST) e o movimento OCUPA UFRN emitiram nota pública em favor da suspensão do calendário acadêmico e contra a PEC55/2016. A ADURN também decidiu por um novo plebiscito realizado na semana seguinte com indicativo de nova paralisação por tempo determinado (29/11 a 13/12) na 
intenção de forçar a suspensão do calendário acadêmico. No CERES (Caicó), apesar de poucas exceções, foi uma semana de pouca movimentação. Porém, a partir do dia 21/11, os docentes retornaram às salas de aula, pressionando os alunos a se fazerem presentes sob ameaças de prejuízos em faltas e notas.

Dessa maneira, no dia 21/11/2016, foram bloqueadas as entradas de todo o CERES/Caicó pelos estudantes-ocupantes. Entre amontoados de cadeiras, correntes fechadas com cadeados e retirada das cadeiras da sala, as aulas foram inviabilizadas. Os professores que aceitassem transformar a aula em aula pública, na praça central, tinham suas aulas efetuadas com sucesso. Os professores que se negavam a colaborar tinham suas aulas interrompidas por batucadas com instrumentos artesanais criados pelos ocupantes. Dois dias após o impedimento ao acesso do campus, a direção do CERES contratou funcionários terceirizados para retirarem as barricadas improvisadas. Foi a partir deste momento que a situação política se tornou mais agressiva e menos pacífica.

Todo o Brasil já se organizava para participar de um ato geral em Brasília no dia 29/11/2016 - dia da votação da PEC 55. Os ônibus dos sindicatos, e as doações financeiras somadas ao pouco dinheiro que havia em caixa do movimento viabilizaram a participação dos integrantes do OCUPA CERES que decidiram ir para Brasília. A partir desse momento a experiência do Movimento OCUPA CERES se pulverizou no tempo e no espaço, nos corações e mentes de todos que ali estavam e que experimentaram novas relações humanas no seio da luta social.

\section{CONCLUSÕES}

A produção do conhecimento científico nas instituições de ensino superior no Brasil deve estar vinculada às demandas sociais prioritárias que possibilitem o fortalecimento de processos políticos, econômicos e culturais voltados para a emancipação da sociedade. Tal pressuposto embasa os diversos eixos teóricos abarcados para as ações de ensino, pesquisa e extensão na área dos movimentos sociais. 
$\mathrm{Na}$ área da educação, as exigências de aprendizados voltados a preparação para a vida social incorporam todas as pedagogias de levante (MARIANA, 2003) enquanto possibilidades reais de desenvolvimento de troca de conhecimentos - alavancados no cotidiano daqueles que ainda se encontram indignados com o projeto de sociedade capitalista e, por isso, se levantam e se insurgem para resistências e superações.

A diversidade teórica, por sua vez, procura estabelecer diálogos entre as várias correntes que analisam, operam, sistematizam e propõe ações concretas para a interlocução entre as temáticas da educação e suas correlações com os movimentos sociais contemporâneos. Esta diversidade teórica, no entanto, possui um ponto em comum de intersecção, seja a autonomia social - exercitada durante as atividades do LAMPEAR no CERES/UFRN.

No caso do movimento OCUPA CERES, a ocupação foi realizada de maneira horizontal, pois não havia liderança nem hierarquia. As comissões estavam estruturadas sempre de maneira voluntária e sem imposições. Dentre as principais comissões, em destaque: Limpeza; Cozinha; Comunicação; Tesouraria; Segurança. Os estudantes-ocupantes se enxergavam dormindo, acordando de cara amassada, indo ao banheiro, cozinhando, lavando roupa, estudando, lutando, discutindo, chorando, sorrindo. A luta social em seu cotidiano insurrecto ultrapassa todos os conhecimentos livrescos e todo o conhecimento bancário que pudesse ser ministrado entre quatro paredes de uma sala de aula.

Todos os dias às 17:00 horas iniciava-se a Plenária do movimento, em praça pública, para que todos pudessem participar. Redes sociais realizavam um contato mais direto com a sociedade em geral. Codinomes estavam no quadro de tarefas, tendo em vista que muitas pessoas entravam e saíam da sala para observar os ocupantes e sua rotina. O uso de drogas era completamente proibido entre os ambientes ocupados, e prezávamos o respeito mútuo em todo o cotidiano da luta social. Não foi utilizada qualquer forma de violência, nem sequer depredação do patrimônio.

A ocupação foi pacífica, apartidária, auto-organizada. Tudo era deliberado entre todos, tudo era livre mediante a anuência coletiva, a luta era frontal contra o preconceito e a opressão - e por isso alguns olhares eram tortuosos e as impressões nem sempre boas. 
Mas tal fato representava um combustível para uma luta mais unificada, mais forte, mais conhecedora e mais persistente. Todos os estudantes-ocupantes tinham plena consciência que eram sujeitos da própria História. A pretensão era um ato maior, mais unido, mais solidário, mais duradouro. A resistência durou até o limite. $\mathrm{O}$ mau sono cansou, a comida acabou junto com o dinheiro e os medicamentos. A saúde andava abalada entre os ocupantes, e a alimentação não passava de arroz e cuscuz nos últimos dias.

E assim tivemos o fim do movimento OCUPA CERES. Após alguns debates, algumas conversas, alguns documentários, alguns olhares que ainda persistem, fica a pergunta: arrependimento? Nenhum. Foi realizado o dever de casa melhor até que os próprios educadores.

Assim, a autonomia social está compreendida, antes de tudo, através de suas configurações históricas. Ou seja, a realidade da luta social - tendo como foco principal os movimentos sociais - que elucida a busca pela autonomia dentro de suas especificidades e contextos históricos, enriquecendo a compreensão a partir das contradições e conflitos inerentes a qualquer processo.

\section{REFERÊNCIAS}

BERNARDO, João. Estado: a silenciosa multiplicação do poder. São Paulo: Escrituras Editora, 1998.

. Transnacionalização do capital e fragmentação dos trabalhadores: ainda há lugar para os sindicatos? São Paulo: Boitempo, 2000.

BEY, Hakim. TAZ: zona autônoma temporária. São Paulo: Conrad Editora do Brasil, 2001.

BRUNO, Lúcia. "Reestruturação capitalista e Estado Nacional”. In: OLIVEIRA, D. \& DUARTE, M. (org) Política e trabalho na escola: administração dos sistemas públicos de educação básica. Belo Horizonte: Autêntica, 1999. 
BRUNO, Lúcia Emília Nuevo Barreto (org). Educação e trabalho no capitalismo contemporâneo. São Paulo: Atlas, 1996.

. “Gestão da educação: onde procurar o democrático". In: OLIVEIRA, D. \& ROSAR, M. (org) Política e gestão da educação. Belo Horizonte: Autêntica, 2002.

CASTORIADIS, Cornelius. A instituição imaginária da sociedade. São Paulo: Paz e Terra, 1982.

FREIRE, Paulo. Pedagogia do Oprimido. Rio de Janeiro, Paz e Terra, 1983.

INTERNACIONAL SITUACIONISTA. Antologia. Lisboa: Edições Antígona, 1997.

MARIANA, Fernando B. Autonomia, cooperativismo e Movimentos dos Trabalhadores Rurais Sem Tera (MST): contribuições educativas para autogestão e pedagogias de levante. Dissertação (Mestrado) - Universidade de São Paulo. São Paulo, 2003. 